\title{
Spatial genetic structure in the saddled sea bream (Oblada melanura [Linnaeus, 1758]) suggests multi-scaled patterns of connectivity between protected and unprotected areas in the Western Mediterranean Sea
}

\author{
Antonio Calò*, Irene Muñoz ${ }^{1}$, Ángel Pérez-Ruzafa, Carlos Vergara-Chen ${ }^{2}$, \\ José Antonio García-Charton \\ Dept. Ecology and Hydrology, University of Murcia, 30100 Murcia, Spain
}

\section{A R T I C L E I N F O}

\section{Article history:}

Received 17 May 2015

Received in revised form 8 November 2015

Accepted 2 December 2015

Available online 18 December 2015

\section{Keywords:}

Genetic connectivity

Marine protected areas

Spatial scale

Sea bream

Mediterranean Sea

\begin{abstract}
A B S T R A C T
Marine protected areas (MPAs) and networks of MPAs are advocated worldwide for the achievement of marine conservation objectives. Although the knowledge about population connectivity is considered fundamental for the optimal design of MPAs and networks, the amount of information available for the Mediterranean Sea is currently scarce. We investigated the genetic structure of the saddled sea bream (Oblada melanura) and the level of genetic connectivity between protected and unprotected locations, using a set of 11 microsatellite loci. Spatial patterns of population differentiation were assessed locally $(50-100 \mathrm{~km})$ and regionally (500-1000 km), considering three MPAs of the Western Mediterranean Sea. All values of genetic differentiation between locations (Fst and Jost's D) were non-significant after Bonferroni correction, indicating that, at a relatively small spatial scale, protected locations were in general well connected with non-protected ones. On the other hand, at the regional scale, discriminant analysis of principal components revealed the presence of a subtle pattern of genetic heterogeneity that reflects the geography and the main oceanographic features (currents and barriers) of the study area. This genetic pattern could be a consequence of different processes acting at different spatial and temporal scales among which the presence of admixed populations, large population sizes and species dispersal capacity, could play a major role. These outcomes can have important implications for the conservation biology and fishery management of the saddled sea bream and provide useful information for genetic population studies of other coastal fishes in the Western Mediterranean Sea.
\end{abstract}

(C) 2015 Elsevier B.V. All rights reserved.

\section{Introduction}

Marine protected areas (MPAs) and networks of MPAs are considered effective tools for the restoration and the management of fishery resources both within their borders (Claudet et al., 2008; Pérez-Ruzafa et al., 2008a; Fenberg et al., 2012) and outside, through the export of propagules (eggs and larvae) and the density-dependent spillover of juvenile and adult individuals (Goñi et al., 2010; Grüss et al., 2011a,b; Harrison et al., 2012; Hackradt et al., 2014).

\footnotetext{
* Corresponding author.

E-mail address: antonio.calo@um.es (A. Calò).

1 Present address: Mountain Research Centre (CIMO), Polytechnic Institute of Bragança, Portugal.

2 Present address: Instituto de Investigaciones Científicas y Servicios de Alta Tecnología (INDICASAT-AIP), Ciudad de Panamá, Panama.
}

The effectiveness of MPAs and networks would depend on a series of criteria both related to the size, location and zoning of the single MPAs (Pérez-Ruzafa et al., 2008b; Almany et al., 2009) and to the relative positioning and spacing of MPAs among them (Jones et al., 2007; Pérez-Ruzafa et al., 2008b). The latter concepts refer to the spatial arrangement of MPAs within networks and strictly rely on the dispersal potential of marine organisms (Green et al., 2014). Connectivity refers to the demographic link between local sub-populations through the exchange of individuals at whatever life stage (Cowen and Sponaugle, 2009) and is inherently related to species dispersal capacity (Jones et al., 2007; Botsford et al., 2009). Connectivity is recognized to have a fundamental importance for conservation issues because it determines the range of distances over which marine fish populations interact and the geographical scales that should be considered in order to properly manage fishery resources (Leis et al., 2011). From this point of view, the 
investigation of connectivity patterns over multiple spatial scales is crucial for the development or the improvement of spatially explicit conservation measures both at local and regional level (Halpern and Warner, 2003; Jones et al., 2007; Almany et al., 2009; Green et al., 2014). At a local spatial scale, the assessment of the level of connectivity between protected and unprotected locations allows to estimate the effectiveness of a MPA to sustain outer non-protected areas or other MPAs within the same network; at a broader scale, it permits the delineation of environmental or anthropogenic barriers to population connections, and allows the characterization of distinct management units.

In spite of its importance, the number of connectivity-based studies in the Mediterranean Sea is still scarce (Calò et al., 2013). Recent studies have focused on the dispersal potential of larvae and/or the movements of juveniles from existing MPAs using, alone or combined, genetic analysis, otolith chemical analysis and biophysical larval dispersal models (Di Franco et al., 2012a,b; Pujolar et al., 2013; Andrello et al., 2013).

Populations genetics is the most frequently adopted approach to assess the structure of fish populations and the gradient of genetic differentiation among spatially distinct units (Palumbi, 2003; Jones et al., 2009). Such information allow to investigate larval dispersal, providing an indirect measure of connectivity (Hellberg et al., 2002; Waples and Gaggiotti, 2006; Jones et al., 2009), and can be used to address specific management issues (González-Wangüemert et al., 2004; Pérez-Ruzafa et al., 2006; Waples et al., 2008). Among the molecular markers currently suitable for these kind of studies, microsatellites have proved to be a powerful tool for investigating population differentiation and gene flow in many fish species (Balloux and Lugon-Moulin, 2002). These markers are highly polymorphic and have fast mutation rates, thus allow to reveal genetic differences even at relatively small spatial scales (Elphie et al., 2012).

In this study, we investigated the genetic structure and patterns of genetic connectivity over multiple spatial scales in a Mediterranean coastal fish, the saddled sea bream, Oblada melanura (Linnaeus, 1758) (Perciformes: Sparidae). Two different spatial scales were considered: at a local scale (i.e. $50-100 \mathrm{~km}$ ) we assessed the level of connectivity between protected and unprotected locations, considering three MPAs of the Western Mediterranean Sea; at a regional scale (i.e. $500-1000$ km) we investigated the presence of connectivity breaks possibly indicating the occurrence of barriers to genetic flows. The saddled sea bream is a common and widely distributed gregarious fish that inhabits rocky reefs and seagrass (Posidonia oceanica) beds (Bauchot and Hureau, 1986; García-Charton et al., 2004) of Mediterranean coastal ecosystems. It is and an important species both for artisanal and recreational fisheries (Claudet et al., 2008; Lloret et al., 2008) and has a relatively short pelagic larval duration (less than 14 days in the Western Mediterranean Sea; Calò et al., submitted), these characteristics making it a good biological model for genetic an connectivity studies in the considered region.

The outcomes of the present study shall provide useful information on: (1) the effectiveness of already established MPAs in sustaining nearby unprotected areas and (2) the spatial scale that should be considered for the correct conservation of spatially explicit management units in the Western Mediterranean Sea.

\section{Materials and methods}

\subsection{Study area and sample collection}

Sampling of 0 . melanura was carried out between September and October 2013. Three sectors (i.e. stretches of coastline of ca. $80-100 \mathrm{~km}$ ) spaced about $400-600 \mathrm{~km}$ from each other were selected along the European coast of the Western Mediterranean Sea (Central France, Northern Spain and Southern Spain) (Fig. 1). In each sector 3 locations were selected (see Fig. 1 for location names and abbreviations). The central location of each sector corresponded to an MPA, respectively: Porquerolles (which became part of the National park of Port-Cros in 2012), Cap de Creus natural park (established in 1998) and Cabo de Palos marine reserve (established in 1995). The other 2 locations of each sector were unprotected and located about $40-50 \mathrm{~km}$ northwards and southwards of each MPA (Fig. 1). In each location, both protected and unprotected, 25-32 juveniles (i.e. individuals of 3-4 months of age), for a total of 258 individuals, were sampled during the night, by snorkeling, using a hand net and a torch. Specimens were firstly euthanized immersing them in a water solution with few drops of $95 \%$ alcohol for minimizing their suffering (Leary et al., 2013) and, after cessation of opercular movements, preserved in absolute ethanol used for genetic analysis. In the laboratory, caudal fins were dissected from each specimen and stored in absolute ethanol at $-20^{\circ} \mathrm{C}$.

\subsection{DNA extraction and PCR amplification}

Total genomic DNA was extracted from a minute section of caudal fin ( 10-20 mg) using Sambrook et al. (1989) protocol.

DNA concentration of each individual was evaluated using NanoDrop 1000 (Thermoscientific) spectrophotometer, using $5 \mu \mathrm{l}$ of ultra-pure water as blank measure. A dilution with polymerase chain reaction (PCR) ultra-pure water was made to standardize each sample to $50 \mathrm{ng} / \mu \mathrm{l}$ of DNA.

Genotypes were examined at a total of 11 polymorphic dinucleotid microsatellite loci: 7 (Omel primers) specifically developed by Roques et al. (2001) for O. melanura and 4 (Dvul primers) crossvalidated in 0 . melanura by Roques et al. (2007) from a set originally developed for Diplodus vulgaris. PCR products were obtained in a MG96Y PCR Thermocycler (AORI Technology Group) using 2 different multiplex mixes for the 2 sets of primers used. For Omel primers, PCRs were performed in a total volume of $10 \mu \mathrm{l}$ containing 50 ng of DNA, 2 mM of $\mathrm{MgCl} 2,0.2 \mu \mathrm{M}$ of each primer, $0.3 \mu \mathrm{M}$ dNTP's, $1 \times$ reaction buffer [ $75 \mathrm{~mm}$ Tris-Hcl, $20 \mathrm{~mm}$ (NH4) 2SO4], $1 \mathrm{mg} / \mathrm{ml}$ of BSA and $0.75 \mathrm{U}$ Taq polymerase (BIOTAQ). PCR conditions were as follows: an initial denaturation step of 5 min at $95^{\circ} \mathrm{C}$, eight cycles consisting of $45 \mathrm{~s}$ at $92^{\circ} \mathrm{C}, 45 \mathrm{~s}$ at $53^{\circ} \mathrm{C}$ annealing temperature, $45 \mathrm{~s}$ at $72{ }^{\circ} \mathrm{C}$ followed by an additional 24 cycles consisting of $30 \mathrm{~s}$ at $92^{\circ} \mathrm{C}, 30 \mathrm{~s}$ at $55^{\circ} \mathrm{C}$ annealing temperature, and $20 \mathrm{~min}$ at $72{ }^{\circ} \mathrm{C}$. For Dvul primers, PCRs conducted in a total volume of $20 \mu$ l containing $50 \mathrm{ng}$ of DNA, $2 \mathrm{mM}$ of $\mathrm{MgCl} 2,0.25 \mu \mathrm{M}$ of each primer, $200 \mu \mathrm{M}$ dNTP's, $1 \times$ reaction buffer [ $75 \mathrm{~mm}$ Tris- $\mathrm{Hcl}, 20 \mathrm{~mm}$ (NH4) 2SO4] and $0.5 \mathrm{U}$ Taq polymerase (BIOTAQ). Amplification conditions were the same as for Omel primers. PCR product was run on 1.5\% agarose gel stained with safe-DNA ${ }^{\circledR}$ before being viewed under UV light and were visualized by capillary electrophoresis using ABI Prism 3730 automated genetic analyser (Applied Biosystems). Allele scoring was done using GeneMapper v.3.5 software (Applied Biosystems, Foster City, California).

\subsection{Data analysis}

All loci were tested for the presence of null alleles using the software MICRO-CHECKER v.2.2.3 (Van Oosterhout et al., 2004). The software POWSIM (Ryman and Palm, 2006) was used to assess the statistical power of the markers used in the study using Chisquared and Fisher's exact tests. A range of predefined levels of expected divergence ( $F s t=0.001,0.005,0.01,0.05$ ) was tested using an Ne (effective population size) of 1000 and $t$ (time of divergence) of 10 . The total number of alleles $(N)$, the number of private alleles (PA), observed ( $\mathrm{Ho}$ ) and expected (He) heterozygosities for each locus and location were obtained with GenAlex v.6. 

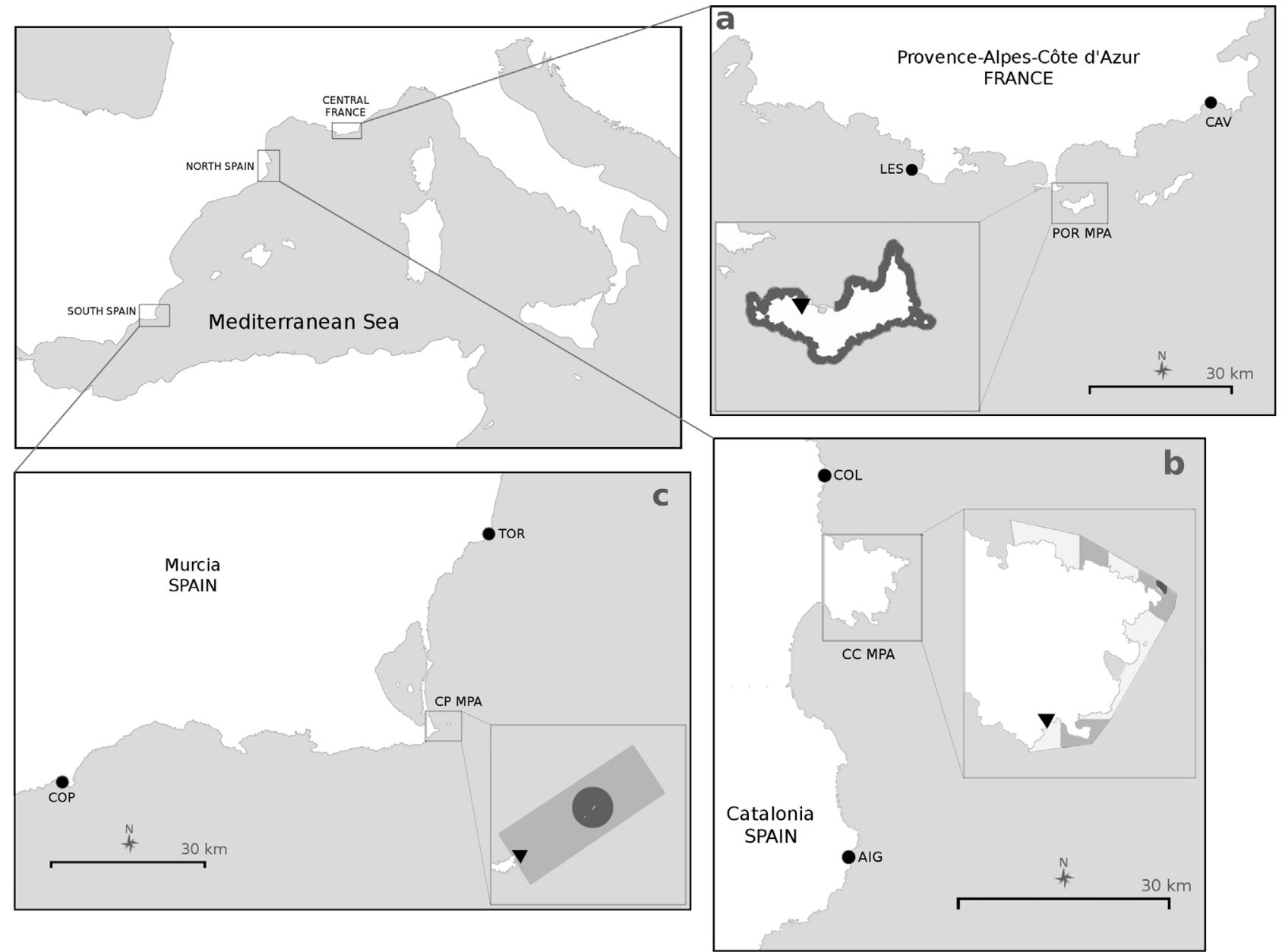

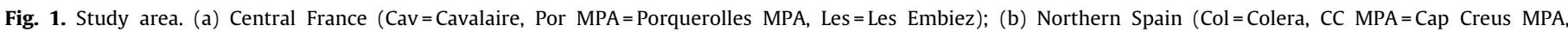

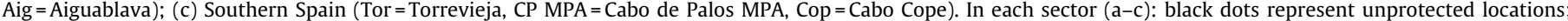

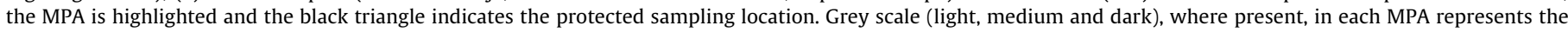
different levels of protection (low, medium and high, respectively).

(Peakall and Smouse, 2006). Standardized allelic richness (AR) and inbreeding coefficient (Fis) and their estimated probabilities were calculated via $10^{4}$ random permutations using FSTAT version 2.3.9.2 (Goudet, 2002). A Student's $t$ test was used among all pairs of locations to test for potential differences in the genetic diversity.

Deviations from Hardy-Weinberg equilibrium (HWE) and linkage disequilibrium (LD) were tested using GENEPOP version 3.4 (Raymond and Rousset, 1995). Where multiple comparisons were tested, the sequential Bonferroni procedure (Rice, 1989) was used to adjust the statistical significance.

Genetic differentiation was investigated by a series of statistical approaches. Firstly, we used the Bayesian approach implemented in the software STRUCTURE (Pritchard et al., 2000), a model-based clustering algorithm that infers the most likely number of clusters in the data. The statistical procedure organizes individuals into a predefined number of clusters $(K)$, with a given likelihood. Ten runs of $10^{6}$ Markov Chain Monte Carlo (MCMC) and $10^{5}$ burn-in-length were carried out using admixture model with no prior local information and $1<K<9$. The most likely $K$ was determined with the criterion of Evanno et al. (2005) using the web tool Structure Harvester v0.6.94 (http://taylor0.biology.ucla.edu/structureHarvester/ ). The method is based on the rate of change of mean posterior probability between 2 different clusters $(\Delta K)$ in function of the number of cluster $(K)$, and the optimal number of clusters is the one that corresponds to the higher value of $\Delta K$.
Genetic differentiation was also investigated through the Discriminant Analysis of Principal Components (DAPC, [Jombart et al., 2010]) as implemented in ADEGENET version 1.3-6 (package used in R software, version 3.1.1; R Development Core Team, 2011). DAPC does not rely on explicit population genetics models, and is useful when the structure is subtle (Jombart, 2008; Jombart et al., 2010; Vander Wal et al., 2013). The dapc function is based on 2 steps: data are firstly transformed using a PCA, then a discriminant analysis (DA) is performed. As recommended in Jombart et al. (2010), for the dapc we retained a number of principal components that corresponded to more than $\sim 90 \%$ of cumulated variance and all the linear discriminants. Two methods for DAPC are available, depending on whether the number of origin samples $(K)$ is known or not, and both were used in this study. In the first case (no information on $K$ ), before performing $d a p c$, the function find.clusters was implemented to identify the optimal number of clusters. This function runs a k-means algorithm after transforming the data through a PCA (a step done in order to reduce the number of variables and to speed up the clustering algorithm, (Jombart, 2013)). K-Means is run sequentially with increasing values of $K$, and different clustering solutions are compared using Bayesian Information Criterion (BIC). The optimal clustering solution is the one that corresponds to the lowest BIC, indicated by an elbow in the curve of BIC values as a function of $K$. In our case all the PCs were retained for the analysis (Jombart et al., 2010) and the maximum number of possible 
clusters was set to $K=9$. In the second case, the function dapc was directly used considering the information on the local samples and the outcomes were visualized through a scatterplot.

Finally genetic differences among sampling locations were assessed by a hierarchical AMOVA in ARLEQUIN 3.5.1.2 (Excoffier et al., 2005), partitioning genetic differentiation among sectors and among locations within each sector. ARLEQUIN was also used to test for Isolation-by-distance (IBD) using a Mantel test, correlating genetic distance versus linear coastal distance between locations and to calculate pairwise Fst between locations. Fst values were then visualised through a principal coordinate analysis ( $P C O A)$ constructed from the genetic distance matrix. Pairwise genetic differentiations were also calculated using the more recent heterozygosity-independent Jost's D (Jost, 2008), which is thought to be a more appropriate statistic for highly variable markers such as microsatellites (Meirmans and Hedrick, 2011). This statistic, based on a bootstrap method (1000 bootstrap repeats) to estimate p-values, was calculated with DEMEtics (Gerlach et al., 2010) (package used in $\mathrm{R}$ software, version 3.1.1; R Development Core Team, 2011).

\section{Results}

All 11 loci considered were polymorphic, with the total number of alleles ranging from 2 to 22 . The most of loci showed a high level of polymorphism (Table 1). The lowest mean number of alleles (2.8) was recorded for locus 'Omel 20', while the highest (18.8) for locus 'Dvul84'. The software MICRO CHECKER detected no evidence for null alleles or genotyping errors due to stuttering or large allele dropout. Simulations using recorded allelic frequencies in POWSIM showed that the markers used in this study have enough statistical power to reveal genetic differentiation at Fst values ranging from 0.001 to $0.05(p=1.000)$.

Values of $\mathrm{Ar}, \mathrm{PA}, \mathrm{Ho}$, He and Fis for each combination of locus $\times$ location are shown in (Tab. 1). Observed values of genetic diversity did not differ significantly between protected and unprotected locations in each sector (Student's $t$ test, $p>0.05$ ). Observed heterozygosity values were relatively high across all loci, apart from locus Omel20 (for which the lowest number of alleles was recorded). Differences in mean values of Ho (range 0.724-0.794) were not significant among locations ( $p>0.05$ for all pairwise Student's t test) similarly to what observed for mean values of He (range 0.752-0.788) and $\mathrm{Ar}$ (range 10.54-11.36) ( $p>0.05$ for all pairwise Student's $t$ test). Only 4 out of 99 tests departed significantly from HWE after Bonferroni correction (locus Omel02 at Les and Tor; locus Omel61 at Cav and CC MPA, see Fig. 1 for abbreviations of location names). No LD was observed between any pair of loci after Bonferroni correction.

The results from the Bayesian approach implemented in STRUCTURE, applying the Evanno's method, are shown in Table A1 (Supplementary material). When we considered all the 9 locations together, the higher value of $\Delta K$ was recorded for $K=3$. Evanno's method needs at least 2 clusters in order to calculate a $\Delta K$ and there is no possibility for a single homogeneous cluster to be selected. This must be the case in our study, although the software suggests a $K=3$, the mean posterior probability indicates that individuals belong to a unique homogeneous group with each individual having approximately the $33 \%$ of probability to come from one of the 3 clusters (Fig. A1, Supplementary material). The same outcome was obtained when the analysis was performed on each sectors separately, revealing in the three cases a higher value of $\Delta K$ for $K=2$, but with no clear evidences for supporting the presence of this clustering pattern.

DAPC analysis was firstly performed without any a priori group information. Using the function find.cluster, the lowest BIC value

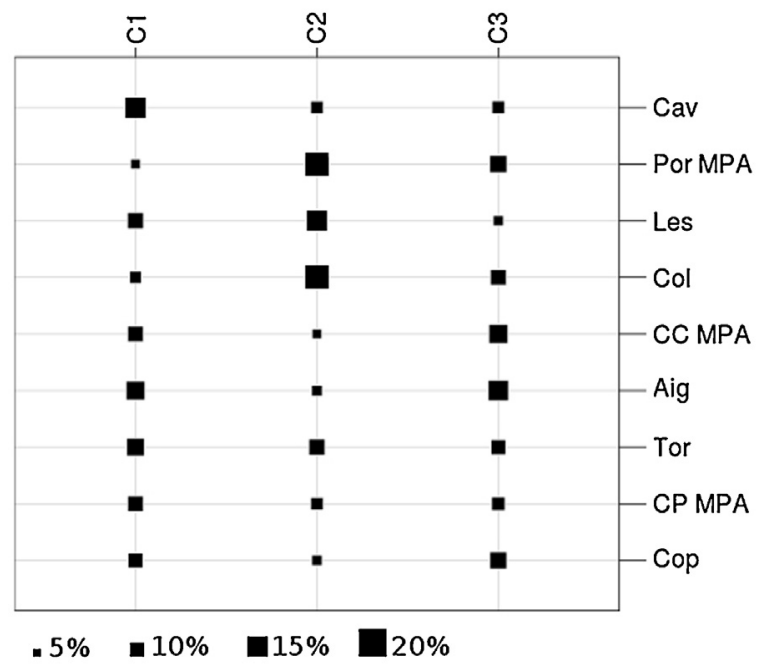

Fig. 2. Repartition of the individual mean posterior probability of the 9 locations considered in the 3 clusters identified by the DAPC without a priori information on the origin samples. The size of the squares is proportional to the values of probability. The meaning of abbreviations to name each location is specified in Fig. 1.

(381.115) corresponded to $K=3$ (Fig. A2 in Supplementary material). For DAPC analysis, 75 PCA axes and two discriminant functions were retained. One cluster (C2 in Fig. 2 and Fig. A3 of Supplementary material) included mainly individuals from Por MPA, Les and Col, which together account for $\sim 50.0 \%$ of the total membership probability of the cluster. In a second cluster (C1) the highest membership probability was recorded for individuals from Cav and Aig (14.9\% and $13.6 \%$ respectively). In a third cluster (C3) the highest membership probability was recorded for individuals from Aig and CC MPA. Individuals from the Southern Spain sector showed similar values of individual membership probability for the three clusters.

In the second dapc analysis, clusters were defined a priori, retaining 85 principal components and the maximum available number of discriminant functions. In a first dapc all the 9 locations sampled were considered separately: the first axis in the scatterplot separated southern locations (Southern Spain sector) from northern ones (Central France and North Spain sector), with Cav, CC MPA and Aig partially separated from Por MPA, Les and Col (Fig. 3a). The second axis grouped Cav and Aig, separating them from CC MPA and the remaining locations. The main groupings identified by the first axis of the scatterplot were used for running other 2 dapc for a better visualization of the outcomes (Fig. $3 b$ and c).

Analysis of molecular variance, performed considering the geographical groupings, suggested no genetic structuring, with no significant differences among sectors and within sectors (Table 2). No Fst comparison resulted significant after Bonferroni correction. Overall, values of Fst, were low with an average value, considering all the 9 locations, of 0.002 . The highest value were recorded between Cav-Por MPA and CP MPA-Por MPA ( 0.0083 for both comparisons) (Table 3 ). PcoA graphically described the genetic divergence computed in pairwise Fst. Although non-significant, a segregation between the group formed by Por MPA, Les and Col and all the other locations was observed along axis 1 of the ordination plot, while axis 2 segregated Cav, Aig and CC MPA from the locations of the Southern Spain sector (Fig. 4), corroborating the results from DAPC analysis. The Jost's D values showed similar results to the Fst values (Tab. 3). Mantel test also resulted not significant, indicating that no relation between geographical and genetic distances occurs. 
Table 1

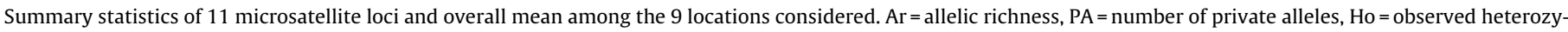
gosity, $\mathrm{He}=$ expected heterozygosity, Fis = inbreeding coefficient.

\begin{tabular}{|c|c|c|c|c|c|c|c|c|c|}
\hline Locus & Cav & Por MPA & Les & Col & CC MPA & Aig & Tor & СР MPA & Cop \\
\hline \multicolumn{10}{|l|}{ Dvul2 } \\
\hline $\mathrm{Ar}$ & 8.68 & 8.66 & 9.45 & 10.80 & 9.00 & 9.71 & 10.46 & 10.00 & 11.00 \\
\hline $\mathrm{PA}$ & 0 & 0 & 0 & 0 & 0 & 0 & 0 & 0 & 0 \\
\hline Ho & 0.929 & 0.800 & 0.600 & 0.719 & 0.760 & 0.759 & 0.767 & 0.600 & 0.880 \\
\hline $\mathrm{He}$ & 0.816 & 0.767 & 0.746 & 0.766 & 0.847 & 0.849 & 0.810 & 0.816 & 0.859 \\
\hline Fis & -0.120 & -0.008 & 0.212 & 0.078 & 0.128 & 0.128 & 0.071 & 0.284 & -0.004 \\
\hline \multicolumn{10}{|l|}{ Dvul33 } \\
\hline $\mathrm{Ar}$ & 4.69 & 2.95 & 3.83 & 2.79 & 2.00 & 2.84 & 2.97 & 3.00 & 2.00 \\
\hline $\mathrm{PA}$ & 2 & 0 & 0 & 0 & 0 & 0 & 0 & 0 & 0 \\
\hline Ho & 0.643 & 0.750 & 0.633 & 0.656 & 0.654 & 0.533 & 0.700 & 0.680 & 0.560 \\
\hline $\mathrm{He}$ & 0.551 & 0.531 & 0.561 & 0.513 & 0.499 & 0.516 & 0.531 & 0.519 & 0.499 \\
\hline Fis & -0.227 & -0.402 & -0.111 & -0.267 & -0.292 & -0.016 & -0.303 & -0.291 & -0.102 \\
\hline \multicolumn{10}{|l|}{ Dvul4 } \\
\hline $\mathrm{Ar}$ & 6.00 & 6.66 & 6.83 & 6.79 & 6.85 & 7.64 & 6.97 & 6.95 & 5.00 \\
\hline PA & 0.000 & 0.000 & 0.000 & 0.000 & 0.000 & 2.000 & 0.000 & 0.000 & 0.000 \\
\hline Ho & 0.741 & 0.719 & 0.828 & 0.800 & 0.731 & 0.724 & 0.793 & 0.840 & 0.792 \\
\hline $\mathrm{He}$ & 0.818 & 0.706 & 0.789 & 0.780 & 0.741 & 0.763 & 0.814 & 0.806 & 0.794 \\
\hline Fis & 0.120 & -0.001 & -0.023 & 0.007 & -0.018 & 0.077 & 0.050 & -0.021 & 0.034 \\
\hline \multicolumn{10}{|l|}{ Dvul84 } \\
\hline $\mathrm{Ar}$ & 19.41 & 18.94 & 19.54 & 18.20 & 17.00 & 19.39 & 17.16 & 17.00 & 19.00 \\
\hline PA & 0 & 1 & 0 & 0 & 0 & 0 & 0 & 0 & 0 \\
\hline Ho & 0.857 & 0.867 & 0.963 & 0.867 & 0.840 & 0.857 & 0.800 & 0.920 & 0.960 \\
\hline $\mathrm{He}$ & 0.926 & 0.908 & 0.932 & 0.922 & 0.917 & 0.935 & 0.927 & 0.916 & 0.933 \\
\hline Fis & 0.092 & 0.068 & -0.009 & 0.081 & 0.067 & 0.104 & 0.154 & 0.016 & -0.009 \\
\hline \multicolumn{10}{|c|}{ Omel02 } \\
\hline $\mathrm{Ar}$ & 11.85 & 12.66 & 13.29 & 13.21 & 13.84 & 11.84 & 13.26 & 12.00 & 14.00 \\
\hline $\mathrm{PA}$ & 0 & 0 & 0 & 0 & 0 & 0 & 0 & 0 & 0 \\
\hline Ho & 0.893 & 0.875 & 0.900 & 0.935 & 0.846 & 0.828 & 0.897 & 0.720 & 0.880 \\
\hline $\mathrm{He}$ & 0.879 & 0.901 & 0.886 & 0.898 & 0.890 & 0.892 & 0.881 & 0.886 & 0.906 \\
\hline Fis & 0.002 & 0.044 & 0.001 & -0.022 & 0.069 & 0.092 & 0.003 & 0.133 & 0.049 \\
\hline \multicolumn{10}{|c|}{ Omel20 } \\
\hline $\mathrm{Ar}$ & 2.00 & 3.54 & 2.00 & 2.79 & 2.96 & 2.98 & 2.85 & 3.00 & 3.00 \\
\hline PA & 0 & 1 & 0 & 1 & 0 & 0 & 0 & 0 & 0 \\
\hline Ho & 0.179 & 0.250 & 0.300 & 0.312 & 0.269 & 0.267 & 0.200 & 0.240 & 0.120 \\
\hline $\mathrm{He}$ & 0.162 & 0.225 & 0.255 & 0.268 & 0.292 & 0.309 & 0.183 & 0.215 & 0.311 \\
\hline Fis & -0.080 & -0.095 & -0.160 & -0.150 & 0.098 & 0.155 & -0.077 & -0.095 & 0.627 \\
\hline \multicolumn{10}{|c|}{ Omel27 } \\
\hline $\mathrm{Ar}$ & 14.94 & 15.16 & 20.49 & 19.04 & 17.81 & 14.44 & 18.30 & 14.00 & 18.00 \\
\hline $\mathrm{PA}$ & 3 & 0 & 1 & 0 & 0 & 0 & 0 & 0 & 0 \\
\hline Ho & 0.885 & 0.774 & 0.733 & 0.938 & 0.846 & 0.828 & 0.833 & 0.880 & 0.720 \\
\hline $\mathrm{He}$ & 0.910 & 0.912 & 0.937 & 0.917 & 0.918 & 0.899 & 0.927 & 0.912 & 0.931 \\
\hline Fis & 0.053 & 0.170 & 0.176 & -0.006 & 0.098 & 0.100 & 0.117 & 0.055 & 0.246 \\
\hline \multicolumn{10}{|c|}{ Omel38 } \\
\hline $\mathrm{Ar}$ & 9.76 & 8.70 & 8.76 & 7.52 & 6.00 & 8.65 & 7.62 & 7.00 & 7.00 \\
\hline PA & 1 & 0 & 0 & 0 & 0 & 0 & 0 & 0 & 0 \\
\hline Ho & 0.821 & 0.938 & 0.700 & 0.594 & 0.731 & 0.667 & 0.767 & 0.760 & 0.840 \\
\hline $\mathrm{He}$ & 0.813 & 0.805 & 0.789 & 0.798 & 0.757 & 0.815 & 0.776 & 0.804 & 0.781 \\
\hline Fis & 0.009 & -0.149 & 0.129 & 0.242 & 0.054 & 0.164 & 0.029 & 0.075 & -0.055 \\
\hline \multicolumn{10}{|c|}{ Omel54 } \\
\hline $\mathrm{Ar}$ & 17.42 & 17.15 & 16.21 & 15.86 & 17.00 & 16.38 & 16.58 & 18.00 & 16.00 \\
\hline PA & 0 & 0 & 0 & 0 & 0 & 0 & 0 & 0 & 0 \\
\hline Ho & 0.964 & 0.906 & 0.933 & 0.812 & 0.880 & 0.800 & 0.900 & 0.920 & 0.800 \\
\hline $\mathrm{He}$ & 0.925 & 0.905 & 0.911 & 0.913 & 0.904 & 0.926 & 0.928 & 0.931 & 0.916 \\
\hline Fis & -0.025 & 0.015 & -0.007 & 0.125 & 0.007 & 0.121 & 0.047 & 0.032 & 0.147 \\
\hline Omel5\& & & & & & & & & & \\
\hline $\mathrm{Ar}$ & 7.80 & 6.60 & 6.68 & 6.60 & 7.96 & 7.64 & 6.97 & 8.00 & 8.00 \\
\hline PA & 0 & 2 & 0 & 0 & 0 & 0 & 0 & 0 & 0 \\
\hline Ho & 0.889 & 0.656 & 0.700 & 0.844 & 0.885 & 0.900 & 0.733 & 0.760 & 0.880 \\
\hline $\mathrm{He}$ & 0.795 & 0.704 & 0.696 & 0.745 & 0.791 & 0.785 & 0.723 & 0.805 & 0.814 \\
\hline Fis & -0.090 & 0.083 & 0.011 & -0.117 & -0.098 & -0.131 & 0.002 & 0.076 & -0.060 \\
\hline Omel6 & & & & & & & & & \\
\hline $\mathrm{Ar}$ & 18.22 & 16.40 & 17.88 & 16.96 & 19.69 & 15.39 & 17.11 & 17.00 & 16.00 \\
\hline $\mathrm{PA}$ & 0 & 1 & 0 & 0 & 0 & 0 & 0 & 0 & 0 \\
\hline Ho & 0.929 & 0.844 & 0.867 & 0.906 & 0.885 & 0.800 & 0.900 & 0.960 & 0.840 \\
\hline $\mathrm{He}$ & 0.923 & 0.911 & 0.913 & 0.924 & 0.926 & 0.909 & 0.925 & 0.918 & 0.923 \\
\hline Fis & 0.012 & 0.058 & 0.067 & 0.035 & 0.064 & 0.136 & 0.008 & -0.026 & 0.110 \\
\hline All & & & & & & & & & \\
\hline $\mathrm{Ar}$ & 10.979 & 10.675 & 11.360 & 10.960 & 10.919 & 10.627 & 10.932 & 10.541 & 10.818 \\
\hline Ho & 0.794 & 0.762 & 0.742 & 0.762 & 0.757 & 0.724 & 0.754 & 0.753 & 0.752 \\
\hline $\mathrm{He}$ & 0.774 & 0.752 & 0.765 & 0.768 & 0.771 & 0.782 & 0.766 & 0.775 & 0.788 \\
\hline
\end{tabular}


Table 2

Hierarchical analysis of molecular variance (AMOVA). d.f. (degrees of freedom), SS (sum of square).

\begin{tabular}{|c|c|c|c|c|c|c|}
\hline Grouping & Source of variation & d.f. & SS & Variance components & Percentage of variation & $P$-value \\
\hline Sectors 1.France & Among groups & 2 & 9.183 & 0.002 & 0.05 & 0.303 \\
\hline 2.North Spain & Among populations within groups & 6 & 25.281 & 0.000 & 0.00 & 0.493 \\
\hline \multirow[t]{2}{*}{ 3.South Spain } & Within populations & 507 & 2139.98 & 4.221 & 99.95 & 0.364 \\
\hline & Total & 515 & 2174.44 & 4.223 & & \\
\hline
\end{tabular}

Table 3

Pairwise comparison between locations. Fst below diagonal, Jost's D above diagonal. See Fig. 1 for location names.

\begin{tabular}{|c|c|c|c|c|c|c|c|c|c|}
\hline & Cav & Por MPA & Les & Col & CC MPA & Aig & Tor & СР MPA & Cop \\
\hline Cav & & 0.0337 & -0.0007 & -0.0187 & -0.0044 & -0.0515 & -0.0080 & 0.0027 & -0.0195 \\
\hline Por MPA & 0.0083 & & 0.0119 & -0.0192 & 0.0004 & 0.0117 & 0.0154 & 0.0450 & 0.0327 \\
\hline Les & 0.0018 & -0.0006 & & -0.0143 & 0.0231 & -0.0157 & 0.0065 & 0.0386 & -0.0059 \\
\hline Col & 0.0008 & -0.0036 & -0.0035 & & 0.0074 & --0.0141 & -0.0176 & 0.0065 & -0.0048 \\
\hline CC MPA & 0.0014 & 0.0004 & 0.0041 & 0.0011 & & -0.0062 & -0.0025 & -0.0018 & -0.0212 \\
\hline Aig & -0.0046 & 0.0015 & -0.0005 & -0.0004 & -0.0007 & & -0.0245 & 0.0079 & -0.0195 \\
\hline Tor & 0.0019 & 0.0017 & -0.003 & -0.003 & 0.0012 & -0.0018 & & -0.0370 & -0.0416 \\
\hline СР MPA & 0.0026 & 0.0083 & 0.0036 & 0.0009 & 0.0024 & 0.0022 & -0.0043 & & -0.0493 \\
\hline Cop & 0.0020 & 0.0056 & 0.0012 & -0.0002 & -0.0004 & -0.0018 & -0.0026 & -0.0040 & \\
\hline
\end{tabular}

\section{Discussion}

The results of the study revealed a high level of genetic diversity in $O$. melanura, expressed as both expected heterozygosity and allelic richness. Similar results were recorded, for the same species, using a different set of microsatellite primers (Gkafas et al., 2013), and in other sparid fish in the Mediterranean Sea (Franchini et al., 2011). High genetic diversity is fundamental for maintaining the adaptability of natural fish populations and sustainable yields in fisheries (Kenchington et al., 2003).

At a local spatial scale (within sectors, $50-100 \mathrm{~km}$ ) protected samples of 0 . melanura were in general well connected with nonprotected ones. The lowest values of Fst and Jost's D were mainly recorded for pairwise comparisons between locations within the same sector, suggesting a high genetic flow between MPAs and locations outside their borders, within each sector considered. Moreover, no differences were found between protected and unprotected samples in terms of genetic variability. This latter result contrasts with the work of Pérez-Ruzafa et al. (2006) that found higher values of both total and standardized allelic richness in protected populations of Diplodus sargus sargus than in unprotected ones, considering two MPAs of the Western Mediterranean Sea (two within the Southern Spain sector and one within the Northern Spain sector of this study). Genetic diversity loss in commercial important species can be a consequence of fishing selection (Pérez-Ruzafa et al., 2006). However, the inference about benefits due to protection from fishing was not an aim of the present study. In fact, the choice to analyse juveniles and consider recently established MPAs (e.g. Por MPA) have to be seen in the light of a study mainly focused on recent genetic connectivity patterns, among MPAs and unprotected areas, rather than MPA effects.

The low level of genetic differentiation, considering all the sampling locations, suggested that local samples of saddled sea bream form a unique, continuous unite along the coast of the Western Mediterranean Sea.

On the other hand, at the regional scale (considering the three sectors, distant $500-1000 \mathrm{~km}$ apart), further analyses revealed the presence of a genetic clustering that has geographic consistency despite the high gene flow. The results from DAPC analysis, performed without a priori information, showed the occurrence of three genetic clusters, whose composition can provide information on the spatial genetic pattern of the species in the study area. The same pattern was corroborated by the ordination plot based on the pairwise Fst between sampling locations, while, although the Bayesian approach indicated the existence of the same number of clusters, there were no evidences for supporting this clustering pattern by this method, as a great homogeneity among the three clusters resulted from the posterior membership probability.

It is difficult to establish with certainty which are the main factors that contributed to the formation of this clustering pattern. The occurrence of the three clusters could be related to an historical isolation of differentiated groups that are currently admixed by ongoing gene flows in the Western Mediterranean Sea. We cannot exclude temporal variation in contributing to the identified clustering pattern. Our sampling design was mainly focused to assess spatial genetic differences and did not include any temporal replicate. This aspect would be certainly worth further investigation. Additional samplings in the study area or over a larger spatial scale would permit a better understanding of the genetic structure of the species in the region.

Although the overall high level of admixture, the cluster C2 shows a composition that seems to reflect the geographical features of the region, being mainly composed by individuals from neighbouring locations, all located in the Gulf of Lions. That could suggest a past isolation of the groups of $O$. melanura inside the gulf or more limited gene flow with the locations off the gulf. Interestingly, although CC MPA and Aig are geographically close to the samples mainly grouped in cluster $\mathrm{C} 2$, individuals from these two locations were the least present in the cluster $\mathrm{C} 2$, while a higher membership probability to the same cluster was found for the individuals of the Southern Spain sector. This outcome could be a consequence of the dispersal characteristics of the saddled sea bream that has a sedentary behaviour during the juvenile/adult phase and its dispersal capability is mainly due to propagules (eggs and larvae) dispersal. Relatively closer locations, separated by habitat discontinuities that do not permit the movement of juveniles and adults, could be less connected than distant ones by propagule dispersal, that for 0 . melanura can take place up to $\sim 100 \mathrm{~km}$ (Calò et al., in publication). The lower genetic purity of group dominance of clusters 1 and 3 could be due to the fact that the study areas correspond to marginal areas. The origin of the cluster 1 could be shifted to the Gulf of Genoa while the cluster 3 might be to the Alboran Sea.

The DAPC analysis with a priori information revealed a separation between the northern part of the study area (Central France and Northern Spain) and the Southern Spain sector. The genetic differentiation between the northern and the southern part of the Western Mediterranean Sea was already pointed out in several recent studies focused on the genetic structure of different 


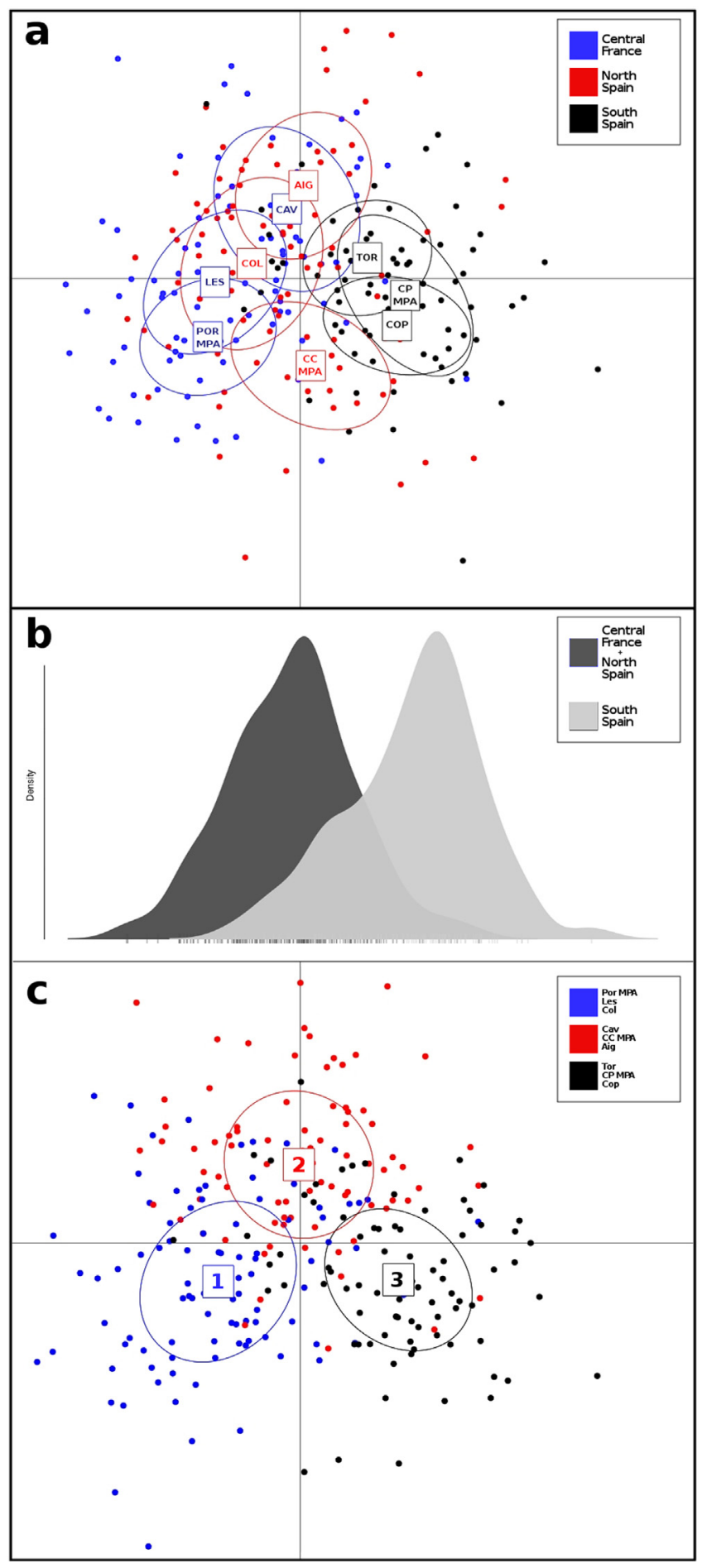

Fig. 3. Scatter plot of the DAPC with a priori information on the origin samples: (a) groups corresponding to the 9 locations sampled (the 2 axes represent the 2 major discriminant analysis eigenvalues); (b) two groups (1 discriminant analysis eigenvalue); (c) three groups (the 2 axes represent the 2 major discriminant analysis eigenvalues). See Fig. 1 for location names.

coastal fish. Schunter et al. (2011a) specifically addressed the role of the Ibiza channel, that in our study separated the Southern Spain sector from the other two sectors considered, by acting as an important barrier for the circulation of the Western Mediterranean Sea, thus determining genetic differentiation across this boundary (but see also, Schunter et al., 2011b). Similar results were found for other commercial species of the Sparidae family

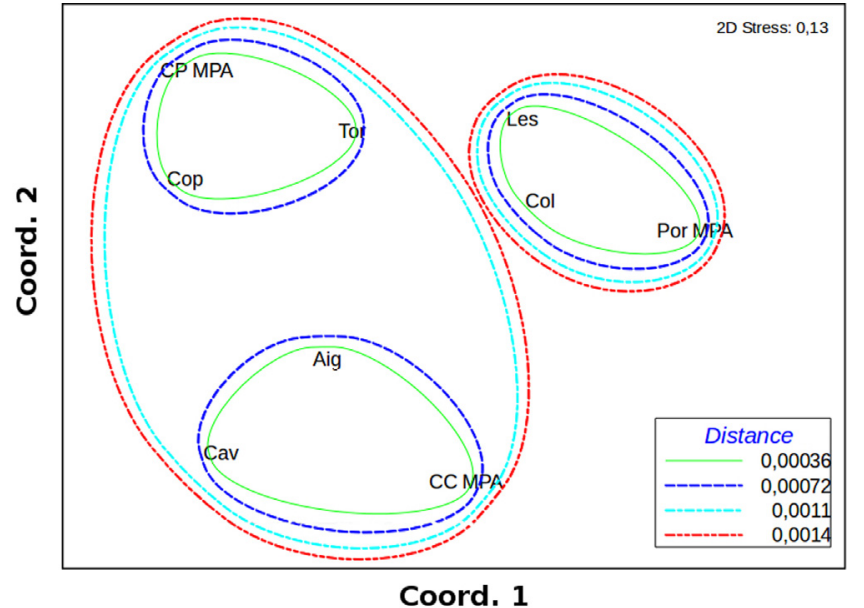

Fig. 4. Principal Coordinates Analysis for O. melanura samples. See Fig. 1 for location names.

(Pérez-Ruzafa et al., 2006; Galarza et al., 2009a,b; for an example with 0 . melanura) and for the red mullet Mullus barbatus (Galarza et al., 2009a,b), along the same stretch of Mediterranean coastline.

Within the northern sectors of our study area (France and Northern Spain) a separation was found between a group formed by Cavalaire, Cap de Creus natural park and Aiguablava and a second group composed by Porquerolles national park, Les Embiez and Colera. This pattern, although subtle, is concordant with the results previously discussed and is likely to be related to geographical arrangement of the sampling locations and the oceanographic circulation of the Western Mediterranean Sea. In particular, Porquerolles, Les Embiez and Colera, could be genetically more similar due to the circulation of the Liguro-Provençal current along the gulf of Lion, separating them from locations outside the gulf. This oceanographic system is one of the most important current in the Mediterranean Sea and follows a south-western trajectory skimming the coasts of France and Spain (Mounier et al., 2005). The Liguro-Provençal current could be responsible of a high dispersal of larvae directly towards the Catalan coast and a low dispersal towards locations inside the gulf of Lion. This could explain the relatively high values of Fst between Porquerolles MPA and Cavalaire, and the high genetic similarity between Cavalaire and the two southern locations of the Northern Spain sector (south of Cap de Creus peninsula). A similar conclusion was reached by Lenfant and Planes (1996), that found a genetic distinction between populations of Diplodus sargus, relatively close to each other, across the western edge of the gulf of Lion.

The detected complex pattern of population connectivity suggests that restrictions to gene flow could be located within the sectors investigated rather than between them. Moreover, the results indicate that the gene flow in the study region may not be related to geographical distances; certain locations showed limited connectivity with their surroundings, whereas other locations showed long distance genetic exchange, as suggested for other fish species (Evans et al., 2010; Villegas Sánchez et al., 2014). In this context, reduced levels of genetic differentiation may be promoted in marine organisms with large effective population sizes complemented with high levels of population admixture of distinct genotypes among locations; however, both conditions could contribute favouring subtle but complex genetic structures, depending on the balance between current-mediated larval dispersal and adult active homing behaviour over small and large geographic scales (Baeza and Fuentes, 2013; Lemer and Planes, 2014; VergaraChen et al., 2014). 
The microsatellite DNA analysis of saddled sea bream over multiple spatial scales indicated a non-significant genetic differentiation between samples and a subtle pattern of genetic heterogeneity at the regional scale, providing an evidence of different levels of gene flow and population connectivity as result of genetic admixture along the locations studied in the Western Mediterranean Sea. The outcome of this study showed that the analysis of genetic differentiation over multiple spatial scales can reveal the presence of different genetic patterns that should be considered for the management of marine resources. Thereby, our study can have important implications for the conservation biology and fisheries management of the saddled sea bream and species harbouring similar biological attributes, and provide useful information for genetic population studies of other ecologically and commercially important coastal fishes. To conclude, it is fundamental to take into account different spatial scales in the genetic analysis of samples representative of marine species for the improvement and/or design of future conservations strategies in the Western Mediterranean Sea. From this perspective, the differences in local and regional patterns of genetic differentiation recorded in this study emphasize the need to consider ecological units, rather than political subdivisions, for the management of marine resources.

\section{Acknowledgments}

This research was supported by the European project 'Initial Training Network for Monitoring Mediterranean Marine Protected Areas' (MMMPA: FP7-PEOPLE-2011-ITN) [grant number 290056]. Irene Muñoz was supported by Fundación Séneca (Murcia, Spain) through the Post-doctoral fellowship 19149/PD/13-N and Carlos Vergara-Chen was partially supported by the "Sistema Nacional de Investigación (SNI) of the Secretaría Nacional de Ciencia, Tecnología e Innovación (SENACYT)" of Panama. Authors wish to thank Dr. Josep Lloret (Univeristy of Girona), Prof. Patrice Francour, Prof. Patricia Pierson, Pierre Vandenbussche and Guillaume Spennato (University of Nice), Serge Moreau and Gilles Garnier (Port-Cros and Porquerolles National Park) and Chiara Adamuccio for assistance during field works. Authors wish to thank the editor and two anonymous reviewers for their useful comments which have helped us to improve the manuscript.

\section{Appendix A. Supplementary data}

Supplementary data associated with this article can be found, in the online version, at http://dx.doi.org/10.1016/j.fishres.2015.12. 001.

\section{References}

Almany, G.R., Connolly, S.R., Heath, D.D., Hogan, J.D., Jones, G.P., McCook, L.J., Mills, M., Pressey, R.L., Williamson, D.H., 2009. Connectivity, biodiversity conservation and the design of marine reserve networks for coral reefs. Coral Reefs 28, 339-351.

Andrello, M., Mouillot, D., Beuvier, J., Albouy, C., Thuiller, W., Manel, S., 2013. Low connectivity between Mediterranean marine protected areas: a biophysical modeling approach for the dusky grouper Epinephelus marginatus. PLoS One 8 , e68564.

Baeza, J.A., Fuentes, M.S., 2013. Phylogeography of the shrimp Palaemon floridanus (Crustacea: Caridea: Palaemonidae): a partial test of meta-population genetic structure in the wider Caribbean. Mar. Ecol. 34, 381-393.

Balloux, F., Lugon-Moulin, N., 2002. The estimation of population differentiation with microsatellite markers. Mol. Ecol. 11, 155-165

Bauchot, M.L., Hureau, J.C., 1986. Sparidae, in: Fishes of the North-Eastern Atlantic and the Mediterranean. Vol. II. pp. 883-907.

Botsford, L.W., White, J.W., Coffroth, M., Paris, C.B., Planes, S., Shearer, T.L., Thorrold, S.R., Jones, G.P., 2009. Connectivity and resilience of coral reef metapopulations in marine protected areas: matching empirical efforts to predictive needs. Coral Reefs 28, 327-337 (Online)

Calò, A., Félix-Hackradt, F.C., García, J., Hackradt, C.W., Rocklin, D., Treviño Otón, J., García Charton, J.A., 2013. A review of methods to assess connectivity and dispersal between fish populations in the Mediterranean Sea. Adv. Oceanogr. Limnol. 4, 150-175.

Claudet, J., Osenberg, C.W., Benedetti-Cecchi, L., Domenici, P., García-Charton, J.-A., Pérez-Ruzafa, A., Badalamenti, F., Bayle-Sempere, J., Brito, A., Bulleri, F., Culioli, J.-M., Dimech, M., Falcón, J.M., Guala, I., Milazzo, M., Sánchez-Meca, J., Somerfield, P.J., Stobart, B., Vandeperre, F., Valle, C., Planes, S., 2008. Marine reserves: size and age do matter. Ecol. Lett. 11, 481-489.

Cowen, R.K., Sponaugle, S., 2009. Larval dispersal and marine population connectivity. Ann. Rev. Mar. Sci. 1, 443-466.

Di Franco, A., Coppini, G., Pujolar, J.M., De Leo, G.A., Gatto, M., Lyubartsev, V., Melià P., Zane, L., Guidetti, P., 2012a. Assessing dispersal patterns of fish propagules from an effective Mediterranean marine protected area. PLoS One 7, e52108.

Di Franco, A., Gillanders, B.M., De Benedetto, G., Pennetta, A., De Leo, G.A., Guidetti, P., 2012b. Dispersal patterns of coastal fish: implications for designing networks of marine protected areas. PLoS One 7 (2), e31681.

Elphie, H., Raquel, G., David, D., Serge, P., 2012. Detecting immigrants in a highly genetically homogeneous spiny lobster population (Palinurus elephas) in the northwest Mediterranean Sea. Ecol. Evol. 2, 2387-2396.

Evanno, G., Regnaut, S., Goudet, J., 2005. Detecting the number of clusters of individuals using the software STRUCTURE: a simulation study. Mol. Ecol. 14, 2611-2620.

Evans, R.D., Van Herwerden, L., Russ, G.R., Frisch, A.J., 2010. Strong genetic but not spatial subdivision of two reef fish species targeted by fishers on the Great Barrier Reef. Fish. Res. 102, 16-25.

Excoffier, L., Laval, G., Schneider, S., 2005. Arlequin (version 3. 0): An integrated software package for population genetics data analysis. Evol. Bioinform. 1, 47-50, Online.

Fenberg, P.B., Caselle, J.E., Claudet, J., Clemence, M., Gaines, S.D., García-Charton, J.A., Gonçalves, E.J., Grorud-Colvert, K., Guidetti, P., Jenkins, S.R., Jones, P.J.S., Lester, S.E., McAllen, R., Moland, E., Planes, S., Sørensen, T.K., 2012. The science of European marine reserves: Status, efficacy, and future needs. Mar. Policy 36, 1012-1021.

Franchini, P., Sola, L., Crosetti, D., Milana, V., Rossi, R.A., 2011. Low levels of population genetic structure in the gilthead sea bream, Sparus aurata, along the coast of Italy. ICES J. Mar. Sci. 69, 41-50.

Galarza, J.A., Czrreras-Carbonell, J., Macpherson, E., Pascual, M., Roques, S., Turner, G.F., Rico, C., 2009a. The influence of oceanographic fronts and early-life-history traits on connectivity among littoral fish species. Proc. Natl. Acad. Sci. U. S. A. 106, 1473-1478.

Galarza, J.A., Turner, G.F., Macpherson, E., Rico, C., 2009b. Patterns of genetic differentiation between two co-occurring demersal species: the red mullet (Mullus barbatus) and the striped red mullet (Mullus surmuletuas). Can. J. Fish. Aquat. Sci. 66, 1478-1490.

García-Charton, J.Á., Pérez-Ruzafa, Á., Sánchez-Jerez, P., Bayle-Sempere, J.T. Reńones, O., Moreno, D., 2004. Multi-scale spatial heterogeneity, habitat structure, and the effect of marine reserves on Western Mediterranean rocky reef fish assemblages. Mar. Biol. 144, 161-182.

Gerlach, G., Jueterbock, A., Philipp, K., Deppermann, J., Harmand, P., 2010 Calculations of population differentiation based on Gst and D: forget Gst but not all of statistics! Mol. Ecol. 19, 3845-3852.

Gkafas, G., Tsigenopoulos, C., Magoulas, A., Panagiotaki, P., Vafidis, D., Mamuris, Z., Exadactylos, A., 2013. Population subdivision of saddled sea bream Oblada melanura in the Aegean Sea revealed by genetic and morphometric analyses. Aquat. Biol. 18, 69-80

Goñi, R., Hilborn, R., Díaz, D., Mallol, S., Adlerstein, S., 2010. Net contribution of spillover from a marine reserve to fishery catches. Mar. Ecol. Prog. Ser. 400, 233-243.

González-Wangüemert, M., Pérez-Ruzafa Á, Marcos, C., García-Charton, J.A., 2004 Genetic differentiation of Diplodus sargus (Pisces: Sparidae) populations in the south-west Mediterranean. Biol. J. Linn. Soc. 82, 249-261.

Goudet, J., 2002. Fstat Version 2.9.3.2. A Program to Estimate and Test Gene Diversities and Fixation Indices.

Green, A.L., Maypa, A.P., Almany, G.R., Rhodes, K.L., Weeks, R., Abesamis, R.A., Gleason, M.G., Mumby, P.J., White, A.T., 2014. Larval dispersal and movement patterns of coral reef fishes, and implications for marine reserve network design. Biol. Rev. 90, 1215-1247.

Grüss, A., Kaplan, D.M., Guénette, S., Roberts, C.M., Botsford, L.W., 2011a. Consequences of adult and juvenile movement for marine protected areas. Biol. Conserv. 144, 692-702.

Grüss, A., Kaplan, D.M., Hart, D.R., 2011b. Relative impacts of adult movement, larval dispersal and harvester movement on the effectiveness of reserve networks. PLoS One 6, e19960.

Hackradt, C.W., García-Charton, J.Á., Harmelin-Vivien, M., Pérez-Ruzafa, Á., Le Diréach, L., Bayle-Sempere, J., Charbonnel, E., Ody, D., Reñones, O., Sanchez-Jerez, P., Valle, C., 2014. Response of rocky reef top predators (Serranidae: Epinephelinae) in and around marine protected areas in the Western Mediterranean Sea. PLoS One 9, e98206.

Halpern, B.S., Warner, R.R., 2003. Matching marine reserve design to reserve objectives. Proc. R. Soc. Biol. Sci. 270, 1871-1878.

Harrison, H.B., Williamson, D.H., Evans, R.D., Almany, G.R., Thorrold, S.R., Russ, G.R., Feldheim, K.A., van Herwerden, L., Planes, S., Srinivasan, M., Berumen, M.L. Jones, G.P., 2012. Larval export from marine reserves and the recruitment benefit for fish and fisheries. Curr. Biol. 22, 1023-1028.

Hellberg, M.E., Burton, R.S., Neigel, J.E., Palumbi, S.R., 2002. Genetic assessment of connectivity among marine populations. Bull. Mar. Sci. 70, 273-290. 
Jombart, T., 2008. Adegenet: a R package for the multivariate analysis of genetic markers. Bioinformatics 24, 1403-1405.

Jombart, T., 2013. A tutorial for Discriminant Analysis of Principal Components (DAPC) using adegenet 1. 3-6.

Jombart, T., Devillard, S., Balloux, F., 2010. Discriminant analysis of principal components: a new method for the analysis of genetically structured populations. BMC Genet. 11, 94.

Jones, G.P., Almany, G.R., Russ, G.R., Sale, P.F., Steneck, R.S., Willis, B.L., 2009. Larval retention and connectivity among populations of corals and reef fishes: history, advances and challenges. Coral Reefs 28, 307-325.

Jones, G.P., Srinivasan, M., Almany, G.R., 2007. Population connectivity and conservation of marine biodiversity. Oceanography 20, 100-111.

Jost, L., 2008. G ST and its relatives do not measure differentiation. Mol. Ecol. 17, 4015-4026.

Kenchington, E., Heino, M., Nielsen, E.E., 2003. Managing marine genetic diversity: time for action? ICES J. Mar. Sci. 60, 1172-1176.

Leary, S., Underwood, W., Anthony, R., Cartner, S., Corey, D., Grandin, T., Meyer, R., Shearer, J., 2013. AVMA Guidelines for the Euthanasia of Animals: 2013 Edition.

Leis, J.M., van Herwerden, L., Patterson, H.M., 2011. Estimating connectivity in marine fish populations: what works best?, in: Oceaography and Marine Biology: An Annual Review. pp. 193-234.

Lemer, S., Planes, S., 2014. Effects of habitat fragmentation on the genetic structure and connectivity of the black-lipped pearl oyster Pinctada margaritifera populations in French Polynesia. Mar. Biol. 161, 2035-2049.

Lenfant, P., Planes, S., 1996. Genetic differentiation of white sea bream within the Lion's Gulf and the Ligurian Sea (Mediterranean Sea). J. Fish Biol., 613-621.

Lloret, J., Zaragoza, N., Caballero, D., Riera, V., 2008. Biological and socioeconomic implications of recreational boat fishing for the management of fishery resources in the marine reserve of Cap de Creus (NW Mediterranean). Fish. Res. $91,252-259$.

Meirmans, P.G., Hedrick, P.W., 2011. Assessing population structure: F(ST) and related measures. Mol. Ecol. Resour. 11, 5-18.

Mounier, F., Echevin, V., Mortier, L., Crepon, M., 2005. Analysis of the mesoscale circulation in the occidental Mediterranean Sea during winter 1999-2000 given by a regional circulation model. Prog. Oceanogr. 66, 251-269.

Palumbi, S.R., 2003. Population genetics, demographic connectivity, and the design of marine reserves. Ecol. Appl. 13, 146-158.

Peakall, R., Smouse, P.E., 2006. Genalex 6: genetic analysis in Excel: Population genetic software for teaching and research. Mol. Ecol. Notes 6, 288-295.

Pérez-Ruzafa, Á., González-Wangüiemert, M., Lenfant, P., Marcos, C., García-Charton, J.Á., 2006. Effects of fishing protection on the genetic structure of fish populations. Biol. Conserv. 129, 244-255.

Pérez-Ruzafa, A., Marcos, C., García-Charton, J., Salas, F., 2008a. European marine protected areas (MPAs) as tools for fisheries management and conservation. J. Nat. Conserv. 16, 187-192.

Pérez-Ruzafa, A., Martín, E., Marcos, C., Zamarro, J.M., Stobart, B., Harmelin-Vivien, M., Polti, S., Planes, S., García-Charton, J.A., González-Wangüemert, M., 2008b. Modelling spatial and temporal scales for spill-over and biomass exportation from MPAs and their potential for fisheries enhancement. J. Nat. Conserv. 16, 234-255.

Pritchard, J.K., Stephens, M., Donnelly, P., 2000. Inference of population structure using multilocus genotype data. Genetics 155, 945-959.
Pujolar, J.M., Schiavina, M., Di Franco, A., Melià, P., Guidetti, P., Gatto, M., De Leo, G.A., Zane, L., 2013. Understanding the effectiveness of marine protected areas using genetic connectivity patterns and Lagrangian simulations. Divers. Distrib. 19, 1531-1542.

Raymond, M., Rousset, F., 1995. GENEPOP (Version 1.2): population genetics software for exact tests and ecumenicism. J. Hered. 86, 248-249,

R Development Core Team, 2011. R: A language and environment for statistical computing. R Foundation for Statistical Computing, Vienna, Austria.

Rice, W.R., 1989. Analyzing tables of statistical tests. Evolution (N. Y). 43, 223-225.

Roques, S., a, Galarza J., Macpherson, E., Turner, G.F., Rico, C., 2007. Isolation and characterization of nine polymorphic microsatellite markers in the two-banded sea bream (Diplodus vulgaris) and cross-species amplification in the white sea bream (Diplodus sargus) and the saddled bream (Oblada melanura). Mol. Ecol. Notes 7, 661-663.

Roques, S., Galarza, J.A., Macpherson, E., Turner, G.F., Carreras-Carbonell, J., Rico, C., 2001. Isolation of eight microsatellites loci from the saddled bream, Oblada melanura and cross-species amplification in two sea bream species of the genus Diplodus.

Ryman, N., Palm, S., 2006. POWSIM: a computer program for assessing statistical power when testing for genetic differentiation. Mol. Ecol. 6, 600-602.

Sambrook, E., Fritsch, F., Maniatis, T., 1989. Molecular Cloning: A Laboratory Manual. Cold Spring Harbour, New York.

Schunter, C., Carreras-Carbonell, J., Macpherson, E., Tintoré, J., Vidal-Vijande, E., Pascual, A., Guidetti, P., Pascual, M., 2011a. Matching genetics with oceanography: directional gene flow in a Mediterranean fish species. Mol. Ecol. 20, 5167-5181.

Schunter, C., Carreras-Carbonell, J., Planes, S., Sala, E., Ballesteros, E., Zabala, M. Harmelin, J.-G., Harmelin-Vivien, M., Macpherson, E., Pascual, M., 2011b. Genetic connectivity patterns in an endangered species: the dusky grouper (Epinephelus marginatus). J. Exp. Mar. Bio. Ecol. 401, 126-133.

Van Oosterhout, C., Hutchinson, W.F., Wills, D.P.M., Shipley, P., 2004. Micro-checker: software for identifying and correcting genotyping errors in microsatellite data. Mol. Ecol. Notes 4, 535-538.

Vander Wal, E., Edye, I., Paquet, P.C., Coltman, D.W., Bayne, E., Brook, R.K., Andrés, J.A., 2013. Juxtaposition between host population structures: implications for disease transmission in a sympatric cervid community. Evol. Appl. 6, 1001-1011.

Vergara-Chen, C., Rodrigues, F., González-Wangüemert, M., 2014. Population genetics of Cerastoderma edule in Ria Formosa (southern Portugal): the challenge of understanding an intraspecific hotspot of genetic diversity. J. Mar. Biol. Assoc. United Kingdom 1-9.

Villegas Sánchez, C.A., Pérez España, H., Rivera Madrid, R., Salas Monreal, D., Arias González, J.E., 2014. Subtle genetic connectivity between Mexican Caribbean and southwestern gulf of Mexico reefs: the case of the bicolor damselfish, Stegastes partitus. Coral Reefs 33, 241-251.

Waples, R.S., Gaggiotti, O., 2006. What is a population? An empirical evaluation of some genetic methods for identifying the number of gene pools and their degree of connectivity. Mol. Ecol. 15, 1419-1439.

Waples, R.S., Punt, A.E., Cope, J.M., 2008. Integrating genetic data into management of marine resources: how can we do it better? Fish Fish 9, 423-449. 